Received: December 12, 2017

Revision received: June 29, 2018

\title{
Research on the Family Language Education for Migrant Children in Northwest China: Based on the sample of Xi'an City*
}

\author{
Fang $\mathrm{Ji}^{1}$ \\ Chang'an University
}

\begin{abstract}
Taking 378 migrant children's families in Xi'an as samples, the present situation of language education in migrant children's families in Northwest China was investigated by means of questionnaires. This paper uses Probit model to analyze the influence of family language attitude and environment on family language education of migrant children. The research conclusions are as follows: (1) Parents of migrant children have the willingness to carry out family language education, but due to income, environment, cultural level and other reasons, the quality of family language education for migrant children in Northwest China is low. (2) Parents' attitude toward family language and family language supervision is the key factor influencing migrant children's acceptance of family language education. When the family language education level is not high, it will also effectively promote the family language education of migrant children.
\end{abstract}

\section{Keywords}

Migrant Children • Family Language Education • Language Attitude • Language Environment

*Supported by National Social Science Foundation Project "Family language life and language planning of migrant children in Northwest China" (18XYY008).

${ }^{1}$ Correspondence to: Fang Ji (PhD), School of Literature, Art and Communication, Chang'an University, Xi' an 710064, China. Email:_diaochongxiaoji6@126.com

Citation: Ji, F. (2018). Research on the Family Language Education for Migrant Children in Northwest China: Based on
the sample of Xi'an City. Educational Sciences: Theory \& Practice, 18(5), 1628-1636.
http://dx.doi.org/10.12738/estp.2018.5.062


The Blue Book for Migrant Children: China's Education Development Report for Migrant Children (2016), published in March 2017, pointed out that the total number of migrant populations in China had reached 247 million by October 1, 2015, and that one out of every six people in the country was in the "floating" category. As the children of the migrant population, the two groups, the floating children and the left-behind children, are among them. The total number is about 100 million (Yang, 2009). In recent years, with the in-depth development of research, the promulgation of various national measures and social concern and support, the school education of migrant children has been gradually solved, but the problem of family education has gradually emerged (Guo \& Liu, 2015). Family is the basic support for migrant children to integrate into the inflow area, the starting point of individual socialization, and the initial place for the formation of world outlook, values and outlook on life (Zhang, 2016). How to carry out family phonetic education is related to the lifelong development of children, the vital interests of millions of families and the future of the country and the nation. China has entered a new period with the improvement of urbanization quality as the core, and the urban agglomeration in the central and western regions will become a new growth pole of floating population (Yang, 2016). With the construction of the Silk Road Economic Belt, the urbanization of Northwest China has intensified, and a large number of left-behind children have been transformed into migrant children. The family problem of migrant children has been highlighted, causing widespread concern in the academic circle. As the proportion of "three generations" of migrant families increases, the number of highly educated migrants has increased; the desire for urban integration has strengthened; the differences between generations and the collision of different languages and cultures in different places have intensified; and the situation of multi-lingual and multi-lingual migrant children's families is becoming more and more complicated. Family education is particularly important for migrant children in the trinity of family education, school education and social education. Therefore, a thorough analysis of the current situation of family language education for migrant children in Northwest China is of great significance for migrant children, their families and even the society.

\section{Research methods}

Xi'an is the central city in Northwest China and also accommodates the largest number of migrant children's families in Northwest China. The researchers also live in Xi'an, which is convenient for data investigation. At least 30,000 to 50,000 migrant workers live in every village in Xi'an, and their children have lost the opportunity to continue education because of economic or school reasons. These children come from more than 20 provinces, cities and autonomous regions in Anhui and Sichuan. Most of their parents are engaged in wholesale and retail trade, catering services and other social services. Many children have missed the age of schooling because their parents are moving around the country. Xi'an Boda School and Xi'an Qinbei Boarding School are two large-scale full-time closed-end schools for children of migrant workers in Xi'an. The school mainly aims at the children of migrant workers around Xi'an, and solves their children's difficulties in school. The two schools are the large-scale children's schools of migrant workers in Xi'an and hold the largest number of migrant children in Xi'an. In this paper, questionnaires and interviews are used to obtain the data. The two cities in Xi'an were surveyed by questionnaires, and the respondents were parents. The questionnaire was brought home by students and uniformly collected the next day. A total of 400 questionnaires were distributed, and 378 qualified 
questionnaires were collected, indicating a recovery rate of 94.5\%. Data were analyzed using SPSS21.0 software and STATA14.0 software. At the same time, this paper also used Probit model to analyze the influence of family language attitude and family language environment on the family language use of migrant children.

\section{Survey on family language education of migrant children}

\section{An investigation on the importance of family language education for migrant children}

Table 1

Parents' Attention to Family Language Education for Migrant Children

\begin{tabular}{lc}
\hline Question: Do you think you value your child's language education? \\
\hline A: very important & $30.69 \%$ \\
B: important & $48.41 \%$ \\
C: commonly & $16.40 \%$ \\
D: unimportant & $4.50 \%$ \\
E: very unimportant & $0.00 \%$ \\
\hline
\end{tabular}

From Table 1, we can see that most of the parents of migrant children are post-80s and post-90s, belonging to the category of new generation of migrant workers. The educational level of the new generation of migrant workers is higher than that of the first generation of migrant workers, who attach great importance to the family language education of their children.

\section{Investigation on the best time of family language education for migrant children}

Table 2

The Best Time for Parents to Consider Family Language Education for Migrant Children

Question: What do you think is the best time for children's language education?

\begin{tabular}{lc} 
A: $0-3$ years old & $17.20 \%$ \\
B: $3-6$ years old & $42.33 \%$ \\
C: 6-12 years old & $33.86 \%$ \\
D: Over 12 years of age & $6.61 \%$ \\
\hline
\end{tabular}

From Table 2, most parents think that 3-6 is the best time for their children to learn a language. Secondly, 6-12 is another important age stage. This is also an increasing expectation of migrant workers to bring their children into the city and pay attention to the role of parents in family language education.

\section{A survey of family language education for migrant children}

Table 3

A Survey of Important Contents in Family Language Education

\begin{tabular}{lc}
\hline Question: What kind of language education do you focus on children? & \\
\hline A: Literate writing & $16.14 \%$ \\
B: Language expression & $27.25 \%$ \\
C: Reading habits & $12.96 \%$ \\
D: Language thinking & $6.34 \%$ \\
E: All of them & $37.31 \%$ \\
\hline
\end{tabular}

From Table 3, parents attach great importance to many aspects of language education, including literacy and writing, language expression, reading habits and language thinking. In terms of individual content, language thinking is the most unnoticed by parents, and language expression is most valued by parents. 


\section{A survey of parents' way of family language education for children}

Table 4

A Survey of Parents' Language Education to Their Children

Question: Which way do you use to teach children language?

\begin{tabular}{lc} 
A: Accompany children to learn & $11.11 \%$ \\
B: School education is OK. & $39.43 \%$ \\
C: Take part in extracurricular training & $4.49 \%$ \\
D: Let children learn by themselves & $27.25 \%$ \\
E: All of them & $17.72 \%$ \\
\hline
\end{tabular}

From Table 4, nearly $40 \%$ of parents believe that language education is a school's job. Even if language education is carried out in the family environment, the proportion of parents who can accompany learning is also low. However, some parents are buying language books and picture books to educate their children. The main reason for this situation is that the parents of these migrant children spend more time and energy on making money while less time and energy to accompany their children, family language education for their children.

\section{Analysis of problems in family language education for migrant children}

\section{Low family economic income level and family language education expenditure}

The economic income of mobile families is not high. The monthly income of mobile families below 5000 yuan reached $82.7 \%$, and that below 3000 yuan reached $61.4 \%$. In the consumption structure of migrant households, the vast majority of the expenditure is spent on basic living expenses such as food, clothing and transportation, and the proportion of expenditure on language education in children's families is relatively low. Educational expenditure mainly focuses on children's tuition fees, books and uniforms, while expenditure on language education, intellectual development and interest cultivation is relatively low.

\section{Low cultural level and professional level of migrant children's parents}

Most of the parents of migrant children only have received junior middle school and senior high school education, while few have a college degree or bachelor's degree or above, of whom $48.2 \%$ of the mothers graduate from junior middle school and below. This low level of education determines that migrant households in the city are more engaged in construction, wholesale and retail trade, catering services and other social services and that vocational level is not high, mainly simple manual labour. Parents have strong occupational randomness and mobility, work hours and intensity, and children often have to adapt to different environments. The educational level of migrant families has a direct impact on their children's educational level, especially the impact from their mothers' educational level and accomplishment (Le, 2014; Zhao, 2004). The lower educational level and occupational level of migrant families have a greater impact on their views on children, their education and educational ability, which also causes existing problems in family language education. 


\section{Poor migrant children's learning environment and living environment}

Floating families have less private housing, and they have poor living conditions and living environment. Most of the migrant families mainly rent houses in the city, and they are more likely to live in urban villages, suburbs, old urban areas, etc. in these areas, the housing area is more crowded and more than half of the children do not have their own independent rooms. These environments are chaotic and noisy, unable to provide children with a stable and quiet learning environment. Most families lack computers, learning machines and other modern educational equipment, while children's home language learning mainly rely on textbook, reference books and reading materials. Considering the poor education level of their parents, they lack the ability and knowledge in children's language education.

\section{High expectation and low attention from parents to their children's language education}

The educational and professional levels of parents of migrant children are generally low. Most parents hope their children can improve their living conditions through hard work. Parents have high expectations for their children's education and career. Compared with higher expectations, migrant children's parents lack specific education guidance experience, methods and knowledge. Coupled with relatively long working hours, they have limited time to spend with their children every day. Also, due to the lack of effective communication, the communication content is shallow and communication methods are simple. If children are growing up without the effective support of family education, they will seek other ways to solve their problems. In addition, children lack effective self-discipline so that they are more inclined to have inadvertent friendship and go astray.

\section{Family language attitude, family language environment and family language education effect}

Some scholars have pointed out that "poverty in education is not the result of poverty, and the attitude of the father and the care of the mother are more important than the level of material needs." Some scholars believe that "in the family environment impact of this kind of variable, the most influential variable on children's academic performance is not the social and economic status of parents, but parents' words and deeds."(Zhou, 2002) Therefore, this paper also explores the effect of family language education for migrant children from family language attitude and family language environment factors.

\section{Variable design}

This paper refers to the variable design of children's language used by $\mathrm{Fu}(2016)$ ( $\mathrm{Fu}, 2016)$. Combined with the actual situation of migrant children, this paper chooses "family language education" and "family foreign language education" as the variable of migrant children, focusing on the analysis of language education in the 
lives of migrant children. The family language education (YYJY) is set to $0-1$ virtual variable: 1 means to implement family language control; 0 means to implement family foreign language education.

This paper defines the main explanatory variables as family language attitude (YYTD) and family language environment (YYHJ). Among them, language attitude is a set of variables for migrant children's parents, including two sub-variables, namely family language requirements (YYYQ) and family language supervision (YYJD). Family language requirements refer to the parents of children with family language education. If there is family language education, the value is 1 , and on the contrary, the value is 0 . Family language environment is divided into two sub-variables: the language education level of mobile family (YYXG) and the surrounding language education level (ZWXG). Family language level refers to the daily language education content of migrant families, which is measured by Likert scale. Peripheral language education refers to the family language education carried out by the neighbors or people who often get in touch with migrant children. Assuming that the neighbors carry out family language education, it will have a very positive impact on the language education of migrant children. When the people around the mobile family have carried out language education, the value will be 1 and the reverse value of 0 . If the people around is 0 , then the value will be 0 directly.

This paper controls the age and gender of migrant children, educational level of parents, language use of family members, family per capita annual income, recreational activities of children and other variables. In view of the endogenous nature between family language monitoring variables and error items, for example, some children's parents will strengthen the family language education because of their occupational characteristics and other reasons. Referring to Herrera and Minetti (2007) tool variable setting method (Herrera \& Minetti, 2015), this paper chooses the average stay-at-home time of parents in the past month as a tool variable, and assigns a minimum value greater than $0(0.001)$ to the missing value of the variable.

\section{Model building}

Combined with descriptive statistical analysis and research needs, this paper establishes a Robit model of heteroscedasticity to analyze the influence of family language attitude and family language environment on family language education of migrant children, which is showed as the following.

$$
\begin{aligned}
& \quad \operatorname{Probit}(Y Y J Y)=\alpha+\beta_{1} \ln (1+Y Y Y Q)_{i}+\beta_{2} \ln (1+Y Y J D)_{i}+\beta_{3} Y Y C D_{i}+\beta_{4} \ln (1+Z W C D)_{i}+ \\
& \delta C_{i}+\varepsilon_{i}
\end{aligned}
$$

Among them, $i$ is the number of research samples. A is a constant term. $\beta_{1}, \beta_{2}, \beta_{3}, \beta_{4}$ and $\delta$ coefficients represent family language requirements, family language supervision, language education, surrounding language education, and a series of control variables. $\mathrm{C}$ is a symbol for a series of control variables. $\mathrm{E}$ is the error term. In order to solve the problem of the right skewness of the distribution of three variables: family language requirement, family language supervision and the education level of the surrounding language, this paper uses the Rossi (2005) method (10), adds 1 to each variable, and then goes to logarithm (Rossi, 2005). 


\section{Empirical research}

Through the correlation analysis of the explanatory variables, the family language education level, family language requirements and parents' education level are significantly and positively correlated at a lower level. Other explanatory variables are not significant, and the correlation coefficient is low. The overall correlation between the explanatory variables is weak. Stepwise regression analysis of the equation shows that no variables are eliminated, which shows that the selection of variables is more reasonable and that there is no multiple commonality between explanatory variables.

There is a possibility of endogenous problems in family language supervision. Therefore, all the regression models are divided into two sets: Porbit model and IvProbit model. The latter model is regressed in two stages by instrumental variable method. Wald test is used to determine whether family language supervision is endogenous or not. Zero hypothesis is that the variables are exogenous. The results show that all the Wald test values in the IvProbit model structure are statistically significant above 0.10 level, and the exogenous test confirms to the IvProbit results. That is, there is no endogeneity in IvADays. Finally, we accept the regression results of Probit model and the Probit model is tested by LR method. The result shows that the model accepts the same variance hypothesis.

In Stata 14.0, regression analysis was conducted to explore whether family language requirements, family language supervision, language education level and surrounding language education level of migrant children's parents have an impact on family language education. The regression results are shown in Table 5.

Table 5

Regression of family language attitude and family language environment on children's family language education

\begin{tabular}{|c|c|c|}
\hline Variables and parameters & Regression coefficient & Standard error \\
\hline Intercept & $0.237^{* *}$ & 0.452 \\
\hline $\ln (1+Y Y Y Q)$ & $0.309^{* * *}$ & 0.327 \\
\hline $\ln (1+Y Y J D)$ & $0.158^{*}$ & 0.275 \\
\hline YYCD & $-0.415^{* * *}$ & -0.718 \\
\hline $\ln (1+\mathrm{ZWCD})$ & 0.113 & 0.236 \\
\hline Observation value & \multicolumn{2}{|c|}{378} \\
\hline $\mathrm{Adj} . R^{2}$ & \multirow{2}{*}{\multicolumn{2}{|c|}{$\begin{array}{c}0.352 \\
11.464^{* * * *}\end{array}$}} \\
\hline$F$ value & & \\
\hline
\end{tabular}

From Table 5, we can see that parents' family language attitude positively affects their children's family language education, and family language requirements and family language supervision also have significant positive impact. The two variables of family language environment have different effects on the family language education of migrant children. It found that: (1) Family language requirements are highly correlated at the level of 0.01 with a coefficient of 0.309 , which indicates that parents' distinct views on family language education are important factors influencing children's acceptance of family language education. (2) Family language education level is negatively correlated with the family language education level of migrant children at 0.01 level, and the coefficient is as high as 0.415 . This shows that the higher the current level of family language education, the less likely the family language education of migrant children. In terms of another variable of 
family language environment, the level of language education around the migrant children's family is not significantly positive correlation, which shows that the level of family language education around the migrant children's neighbours or acquaintances has little influence on the children's family language education. This is mainly because of the instability of migrant children's family living, who often change their places of living, resulting in the change of the acceptance of the surrounding environment. Migrant children generally have more than one playmate, so they suffer from a deeper impact from the limitation of individual family language education.

\section{Conclusion}

This paper takes the migrant families of the new generation of migrant workers in Northwest China as the research object, and studies the current situation and influencing factors of family language education for migrant children. The results show that the quality of family language education for migrant children in Northwest China is low; although parents have the desire and ideas to carry out family language education, it is restricted by the parents' income level, living environment, education level, occupation level and other reasons, which leads to the poor performance of family language education of migrant children. Further research finds that parents' family language attitude and family language supervision are the key factors for migrant children to receive family language education. Even if the family language education level is not high, it will also effectively promote family language education for migrant children. Parents' attitudes towards family language and family language education are important prerequisites for family language education of migrant children. However, in fact, the proportion of the new generation of migrant workers holding this attitude is low. Coupled with the fact that their overall economic and living conditions are not good, it results in poor family language education status of migrant children. Therefore, in the process of national economic development and urban-rural integration, it is very important to promote family language education for migrant children.

\section{References}

Fu, G. (2016). A Study on the influence of parents' migrant work on language use of rural children: Taking funing county of Jiangsu Province as an example. Applied Linguistics, (1), 18-25.

Guo, Q. H., \& Liu, Y. F. (2015). Family education guidance for floating children under the background of multiple subjects. Journal of China Youth College for Political Sciences, 34(3), 31-35.

Herrera, A. M., \& Minetti, R. (2015). Informed finance and technological change: Evidence from credit relationships. Journal of Financial Economics, 83(1), 223-269. http://dx.doi. org/ 10.1016/j.jfineco.2005.12.001

Le. W.L. (2004). Analysis of the influencing factors of family education for floating population. Journal of Ningbo University (Education Science Edition), 26(3), 1-7.

Rossi, S. (2005). Patents, capital structure and the demand for corporate securities. Working Paper, www.ssrn.com, (9), 1-67. http://dx.doi. org/ 10.2139/ssrn.686029 
Yang, D. P. (2009). Education blue book: China education development report. Beijing: China Social Sciences Literature Press.

Yang, G. (2016). Evaluation of left behind children's policy and social support -- Based on the survey and analysis of Jiangsu Province. Social Governance, (6), 74-83.

Zhang, C. X. (2016). Practical exploration of family education for migrant children from the perspective of ecosystem theory. Zhengzhou: Zhengzhou University Press.

Zhao, J. (2004). Qualitative research on family rearing patterns of floating population. Youth Studies, (8), 1522.

Zhou, F. (2002). Problems and educational intervention of family education for children of floating population. Educational Science Research, (11), 54-55. 